\title{
Modeling of the Gas Transmission Reliability as a Component of Economical Security of Ukrainian Gas Transmission System
}

\author{
Halyna Zelinska \\ Department of Applied Economics \\ Ivano-Frankivsk National Technical \\ University Of Oil And Gas \\ Ivano-Frankivsk, Ukraine \\ https://orcid.org/0000-0003-2175-4883
}

\author{
Irina Fedorovych \\ Department of Applied Economics \\ Ivano-Frankivsk National Technical \\ University Of Oil And Gas \\ Ivano-Frankivsk, Ukraine \\ https://orcid.org/0000-0002-7139-6327 \\ Nataliia Yurchenko* \\ Department of Social Medicine and \\ Public Health \\ Ivano-Frankivsk National Medical \\ University \\ Ivano-Frankivsk, Ukraine \\ https://orcid.org/0000-0001-8635-6515
}

\author{
Uliana Andrusiv \\ Department of Theory of Economics \\ and management \\ Ivano-Frankivsk National Technical \\ University Of Oil And Gas \\ Ivano-Frankivsk, Ukraine \\ https://orcid.org 0000-0003-1793-0936
}

\begin{abstract}
The article focuses on the reliability of the gas pipeline system. The decrease in the reliability of the gas transmission system can be considered from two sides. On one hand, it increases the expanses. On the other hand, there is a threat to public health and the loss of human and natural resources. It is proved that the main reason for reducing the reliability of the natural gas transmission process is the significant equipment ageing. The possibility to increase the reliability of the linear part of the main gas pipelines by conducting a quality repair system and equipment upgrades is substantiated. It is determined that the failure rate depends on the diameter and the number of the pipelines. The model of the failure rate process and average recovery time is offered to reduce the financial expenses of the enterprise.
\end{abstract}

Keywords - reliability, costs, accidents, economic benefits, failures, forecasting

\section{INTRODUCTION}

The most important task of Ukraine's energy security system is to provide the reliability of the inner gas transmission system. To maintain its elements and prevent their premature deterioration is technically difficult and expensive. The core reasons of the significant repair expenses in the gas pipeline system and their sharp increase at last years are: (1) increasing the average operating age of the gas transmission lines, (2) the construction of a large number of them in areas with high soil aggressiveness, high wetlands. That's why these expanses require the deeper economic justification to reduce financial costs and obtain economic benefits. These circumstances underline the great relevance and importance of the study of the economic problems of the gas transmission lines repairing.

\section{LITERATURE REVIEW}

The attention of scientists and practitioners to the reliability and security of fuel and energy resources (FER) supply is increasing. In particular, different groups of indicators are being investigated in the context of the analysis of the economic security of the state [1]: technical, technological, social, economic, environmental or by individual product determinants (gas safety, oil safety, coal safety). Dergachova V. and Pysar N. [2] are the authors of the differential equations, taking into account the prices for fuel and energy resources, export, import, as well as the mutual influence of certain types of energy resources output on other ones. Last years, the energy supply security has become one of the most pressing political issues for the countries of Central and Eastern Europe [3]. At the same time, many scientists [4] draw attention to the relationship between energy security policies, environmental security and sustainable development.

Such scientists as Magomedov R., Paizulaev M., Gebel E. [5] studied the reliability of oil pipelines working under aggressive conditions. A group of scientists [6] have estimated the probability of corrosion failures in an oil and gas pipeline based on a fuzzy logic approach. Also the methodology for assessing the reliability of gas supply to the natural gas pipeline system was developed and three aspects of uncertainty and the hydraulic characteristics of the natural gas pipeline system was considered [7].

In their studies [8], researchers Eser P., Chokani N., Abhari R. found that a projected reduction in domestic European gas production would lead to a $12 \%$ deficit in EU gas demand by 2030. And they offered two different strategies to overcome the shortage: (1) to increase liquefied natural gas imports from various global sources against increasing supply of the Russian gas pipeline through the Nord Stream, (2) a new model of the gas system that is capturing the market as well. The potentials of studying the effect of failures and recovery coefficients on integral reliability of gas distribution systems are also considered by scientists [9]. 
A comprehensive assessment of the risks of gas pipelines exploitation [10] as developed. It makes possible to predict the gas pipeline crashes and their possible consequences. have proposed Also a comprehensive method of quantitative risk analysis for the gas transportation system, which consists of accident risk assessment, impact analysis and risk assessment [11] was offered. Researchers [12] evaluated the integrity of gas pipelines and evaluated their management, where they proved that the result of their functioning depends on the effective management.

\section{MAIN PART}

As an applied field of knowledge, the science of reliability is based on fundamental mathematical and natural sciences. It studies the patterns of change in the quality of technical devices and systems and provide its trouble-free exploitation with the minimum time and resources expense.

The reliability of gas transmission lines, like any technical object, is defined as the ability to perform the specified functions, while maintaining the specified performance over time. However, being a complex feature, depending on the purpose and conditions of operation, reliability may include failure-free, durability, maintainability or certain combination of these features.

The specific features of reliability are: (1) the time factor as the change in initial parameters during the operation of the equipment is estimated, (2) an object behavior prediction that maintains its original parameters (quality indicators).

The reliability of the gas supply system, its subsystems and facilities depends on many factors, among which are the following:

- the level of reliability of the elements of the equipment included in the system;

- the operation and management level of the system;

- the composition of the elements included in the system and the structure of the relations between them;

- the amount and structure of gas reserves;

- management efficiency.

The reliability and technological characteristics of the elements of these systems (average time of emergency and scheduled repairs, await repair time, the elements performance) largely depend on the quality of the equipment and the level of operation of the system. The values of these parameters are limited by the level of scientific and technological progress achieved and the economic feasibility of additional costs for the technology improvement. These factors can change both through the rational use and allocation of costs for the system's creation and development, as well as the costs for reserves, and also by increasing of these costs. So, reducing the reliability level of the gas pipeline results both in the weakening of the economic security of the state and in the fatal consequences for humans.

When planning repairs, upgrades and reconstruction of gas transmission lines it is important to prevent gas pipeline failures and crashes. Therefore, it is necessary to pay the greatest attention to the amount of equipment depreciation of the linear part of the pipeline. However, the service life can be extended as a results of inspections and diagnostics of the technical condition of the gas pipelines. That's why it is necessary to take into account the volume of natural gas transportation planned; safety of gas transmission lines; gas pipelines demolition.

The main characteristics of the gas transmission lines reliability: trouble-free, durability and maintainability.

We have determined that gas transmission lines may be in one of the following states: (1) loaded, (2) scheduled preventive repair, (3) forced (emergency) idle time. As a result of the influence of various external connections of a random nature, the gas transmission lines in the process of exploitation passes from one state to another. The transition is made at random times. Only sometimes it is possible to predict the exact residence time of gas transmission lines. But even so, there is uncertainty about the onset of the moment of change of state.

The stability of the gas transportation system is determined by the material base, which includes the gaspumping machinery and the linear part of the main gas pipelines. Only highly qualified personnel can satisfy the needs of its high efficiency and reliability. Predictions of gas pipeline failures and rapid elimination of the consequences of accidents are particularly relevant at modern, powerful gas pipelines.

Determination of economic losses caused by accidents is important for the gas transmission company. Economic risks are not subject to mandatory assessment by supervisory authorities. Therefore, the permitted levels of these risks are not regulated. The economic risks assessment model based on economic feasibility and efficiency of gas pipeline further operation was offered. We find the economic losses caused with the failures and accidents determination to be particularly important for gas transmission companies.

We offer to determine the enterprise's economic losses by the following steps:

- The main losses from failures of a gas pipeline are the cost of direct gas losses $L d$, losses during gas pipeline downtime $L d t$ and the repair cost $L r$. It also includes losses from possible damage to technical facilities and communications, crossing the gas pipeline at the accident site $L t$ and the social costs caused by the possible people displacement or the restoration of buildings $L s$.

- Gas leakage losses from gas leak in monetary terms is

$$
L_{d}=(V 1+V 2) \cdot P_{g}
$$

where $V I$ - the volume of gas exiting the pipeline by the time the taps are closed;

$V 2$ - the volume of gas exiting the pipeline after the taps have been closed until the pipeline is fully released;

$P g$ - the price of 1 cubic meter of gas.

- $\quad$ Losses during gas pipeline downtime $L d t$ : 


$$
L d t=K d n^{*} V d^{*} P g+P p
$$

where $K d n$ - downtime, days;

$V d$ - daily volume of gas transportation;

$P p$ - the penalties according to the contract.

- The repair cost depends on the type of failure, the amount of equipment involved, the availability of the facility and the repair type.

- Losses from possible damage to technical facilities and communications include the amount of compensation for repair or the losses incurred by the pipeline owner if these facilities are on his balance sheet.

- Social loss is associated with the possible displacement of people or the restoration of social facilities that have been affected by the failure. Economic social losses are estimated if a threat to social objects that border or are in the natural areas of the main gas pipelines affected. The magnitude of these losses depends on the type of failure and the distance to the social object. In the case of insurance policies, the total loss may be reduced by the amount of insurance claims.

Therefore, by determining the economic losses by individual components, gas transportation companies will be able to determine the order of precautionary feasibility measures to minimize costs.

Analyzing the statistical information for the period 20162018 , it was found that in 2018 , on the linear part of the gas pipelines, e. g. "Prycarpattrasgaz" department, no failures were recorded in contrast to previous years. They reported on 4 failures in 2016 and 2 in 2017. It should also be noted that at the end of 2016, the repair program for the company was completed by $57 \%$. The repair plan was not implemented due to the delay in the supply of insulation materials. In the following years, the plan for repair works averaged $63 \%$. Therefore, the management of the company should pay more attention not only to the supply logistics, but also to the new technologies implementation to improve the exploitation of fixed assets.

The analysis of statistical data for 2016-2018 showed that the current state of the GTS enterprises of Ukraine is a reflection of the general economic crisis phenomena. More than $50 \%$ of gas pipelines have been operated for over 30 years.

The structure of gas pipelines in terms of service includes: up to 10 years - 3\%; 10-15 years - 5\%; 16-20 years - 9\%; $21-30$ years $-32 \%$; over 30 years $-51 \%$. Powerful gas pipelines such as "Soyuz", "Progress" and "UrengoyPomary-Uzhgorod" were built and used for transit only. Most of the compressor stations of these gas pipelines have imported high-tech equipment, but a large part of it already requires to be changed or renovated. More than 700 gas pumping units installed at compressor stations of gas pipelines of Ukraine. Almost $30 \%$ of them have already passed the final date of its exploitation period according to the documents. Therefore, their efficiency is often $24-26 \%$, there is an overspending of fuel gas, and, consequently, a decrease in the productivity and reliability of the main gas pipelines as a whole.

Accidence is a contrast to a reliable energy transportation process. The largest number of accidents on gas transmission lines occurs due to defects in pipe metal, as well as to the gas transmission systems operation rules violations, arising as a result of poor-quality welding of patches when cutting openings for the installation of rubber balls. Many accidents are caused by temperature deformation of the gas pipeline.

The failure rate of gas pipelines shows an indicator $\lambda(t)$, which can also show the intensity of failures [13].

$$
\lambda(t)=\frac{n}{\Delta \operatorname{tn}(t) L},
$$

where $n$ - the number of failures during $\Delta t$ over the entire length of the pipeline;

$n(t)$ - the number of non-failing elements by the time $t$;

$L$ - the length of the pipeline.

For main gas pipelines, this value is given depending on the diameter as the ratio of the number of days of emergency status to the entire period of operation (year). The failure rate also depends on the number of lines and the diameter of the pipeline (Table 1).

TABLE I. THE DEPENDENCE OF THE FAILURE RATE OF THE GAS TRANSMISSION LINES ON THE NUMBER OF PIPES AND THEIR DIAMETER

\begin{tabular}{|c|c|c|c|c|}
\hline \multirow{2}{*}{$\begin{array}{c}\text { Diameter, } \\
\text { mm }\end{array}$} & \multicolumn{4}{|c|}{ The failure rate (at 1/hour*10 ${ }^{-3}$ ) for different lines } \\
number N
\end{tabular}

Formed by the authors using [10]

For example, here are sections consisting of several lines of gas pipelines in the territory of Western Ukraine, namely: gas pipelines "Belchevolitsa-Dolina" and "IvacevichiDolina-III"; gas pipelines "Bogorodchany-Dolina "Torzhok-Dolina"; gas pipelines "DUD-I", "DUD-II" and "Progress"; gas pipelines "Pasichna-Dolyna", "Bogorodchany-Dolyna", "UPU" and "Soyuz"; gas pipelines "Uhersko-Ivano-Frankivsk", "Uhersko-Ivano-FrankivskChernivtsi", "Pukenichi-Dolyna" and "KZU-II" and others.

It is possible to approximate the failure rates for pipelines of other length using the following coefficients (Table 2).

TABLE II. COEFFICIENTS FOR DETERMINING THE FAILURE RATE OF GAS PIPELINES OF DIFFERENT LENGTHS

\begin{tabular}{|c|c|c|c|}
\hline \multirow{2}{*}{$\begin{array}{c}\text { Length, } \\
\mathbf{k m}\end{array}$} & \multicolumn{3}{|c|}{ The number of pipes N, diameter d, mm } \\
\cline { 2 - 4 } & $\begin{array}{c}\mathrm{N}=1 \\
\mathrm{~d}=1020\end{array}$ & $\begin{array}{c}\mathrm{N}=2 \\
\mathrm{~d}=1220\end{array}$ & $\begin{array}{c}\mathrm{N}=3 \\
\mathrm{~d}=1420\end{array}$ \\
\hline 1000 & 1,0 & 1,0 & 1,0 \\
\hline 2000 & 1,53 & 1,58 & 1,60 \\
\hline 3000 & 2,00 & 2,08 & 1,15 \\
\hline
\end{tabular}

b. Formed by the authors using $[10]$ 
Accidents and failures on gas transmission lines are discrete quantities that are independent of each other, and this allows us to predict these figures with the help of a statistical and mathematical apparatus. Thus, we have determined that the statistics on the failure of the linear part of gas pipelines are quite consistent with the exponential probability distribution function.

The additional verification of the exponential distribution law compliance with the actual data for the calculations fully confirmed the assumption formulated in the paper about the probability distribution law and a number of the following important properties:

- time between gas pipeline failures is described by exponential law:

$$
F_{1}(t)=1-e^{-\lambda t},
$$

with a distribution density:

$$
f_{1}(t)=\lambda e^{-\lambda t}
$$

- the probability of the number of failures in a gas pipeline of length $\mathrm{L}$ in a single gas line at time $\mathrm{T}$ is described by Poisson's law:

$$
p\{n\}=\frac{(\lambda L T)^{n}}{n !} e^{-\lambda L T},
$$

where $\lambda$ is a constant positive value.

- the failure rate of the commissioned gas pipelines decreases monotonically over time, and the failure rate increases over time for gas pipelines operated for more than 20 years.

Our additional studies have shown that in most cases it is possible to use an exponential representation of the law of distribution (Figure 1).

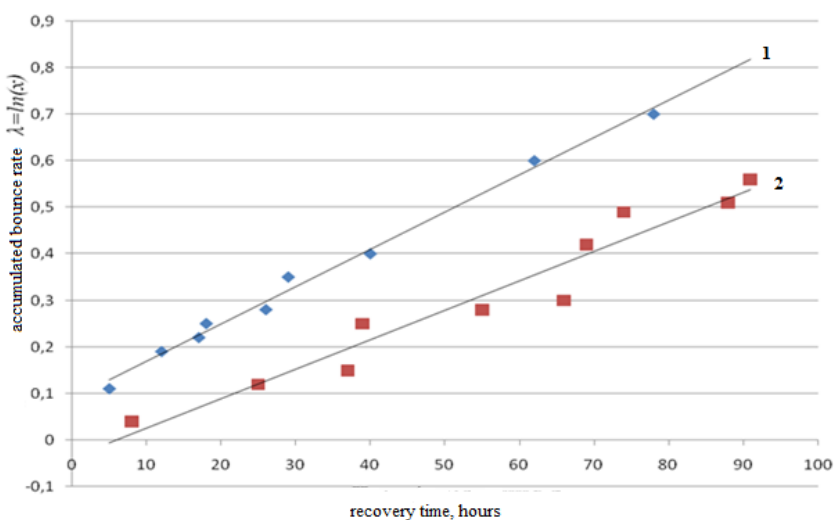

Fig. 1. Direct correspondence of experimental data to the exponential law of distribution of the operating time of the linear part of gas pipelines: 1 - diameter $1220 \mathrm{~mm} ; 2$ - diameter $1420 \mathrm{~mm}$

c. Source: developed by authors on the basis of commercial statistics of Western Ukrainian Gas Pipelines Department for 2017-2018

Recovery time distribution function is represented as:

$$
F_{2}(t)=1-e^{-\mu t},
$$

and can be used to build methodological bases for reliability assessment.

The failure rate increases with the length of the pipeline, its corrosion etc. Our processing of a large number of statistics shows the existence of a linear relationship between the specific failure rate and the diameter of the pipeline:

$$
\lambda=a_{1} d+b_{1}
$$

The coefficient $b$ here was determined based on the built-in functions of the trend curves of the EXCEL program and are relevant $a_{l}=0,89^{*} 10^{-10} ; b_{1}=0,987 * 10^{-8}$.

Figures 2, 3 show the results of the study: a graphical interpretation of the dependence of the failure rate and the average recovery time from the diameter of the pipeline for the actual data and their trends. As we can see, we have a high accuracy of getting theoretical dependencies on the actual data. As we can see, the actual data are highly correspondent to theoretical trends.

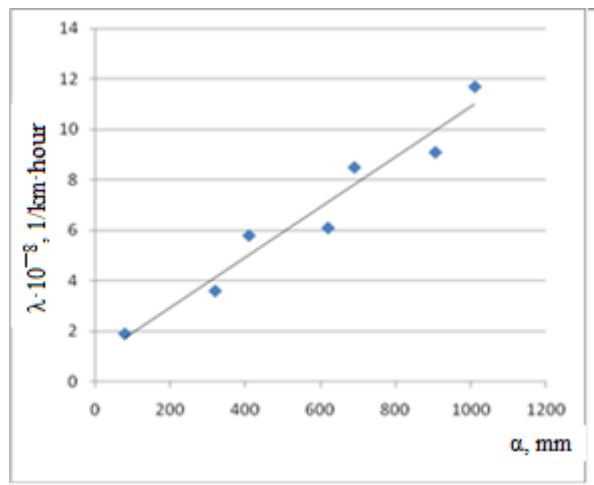

Fig. 2. The dependence of the specific failure rate on the diameter of the pipeline

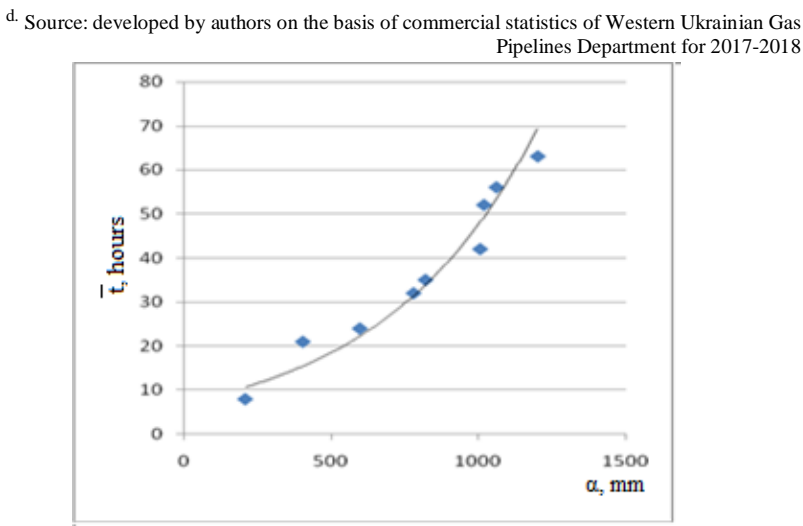

Fig. 3. The dependence of the average recovery time on the diameter of the pipeline e. Source: developed by authors on the basis of commercial statistics of Western Ukrainian Gas
Pipelines Department for 2017-2018

The analysis showed that the increase in $\lambda$ when pipeline diameter increasing can be explained by the following reasons: (1) when the weight of pipes increases, the loading and unloading operations become more complicated, which increases the likelihood of damage to the pipes during these 
operations, (2) jointing of pipes during welding is complicated with increasing diameter even if the specifications are met, (3) the temperature regime of large diameter gas pipelines during operation is more strained compared to small diameter pipelines, which can lead to temperature deformations.

Another important indicator of reliable operation of the pipeline is the average recovery time (9), or the recovery intensity $\mu$, which is the inverse of it.

$$
\bar{t}=\frac{1}{n} \sum_{i=1}^{n} t_{i}
$$

where $t i$ is the time of elimination of the $\mathrm{i}$-th accident;

$n$ - the total number of accidents.

Recovery time depends on the nature of the accident, the season, the gas pipeline route conditions, the distance between the accident and the emergency repair points, the equipment of the emergency crew, as well as the qualifications of the personnel involved in the recovery process. The repair time of a gas pipeline of the same diameter varies widely. However, the dependence of the mean recovery time on the diameter can be approximated by the following dependence:

$$
\bar{t}=a_{2} d^{2}+b_{2},
$$

The values of the coefficients $b$ (8) are determined by forecasting. We obtained the following results:

$$
\mathrm{a}_{2}=3,07^{* 10-5} ; \mathrm{b}_{2}=8,97 \text {. }
$$

The figure $2 \mathrm{~b}$ shows the curve of dependence (10) and the actual values of $\bar{t}$ obtained as a result of statistical processing. The growth of $\bar{t}$ with increasing diameter is explained by the following reasons: (1) the length of the pipeline rupture increases as the diameter increases, causing the increased amount of repairing, (2) as the diameter increases, the amount of earthworks and welding works increases also, (3) jointing of pipes during repair works on gas pipelines of large diameter sharply complicates and takes a large share of the total time of accident elimination.

One of the main characteristics that determines the financing strategy for gas transmission lines is the financial loss caused by accidents. Predicting the magnitude of losses in the pipeline section in the event of accidents determines the priority in financing the repair works of the site.

Keeping in mind that the cost of gas is increasing, it is necessary to determine the financial loss of the enterprise from the amount of gas lost and to determine the main factors that led to the occurrence of accidents. The complexity of the gas transmission lines accident estimation algorithm is primarily due to the fact that its magnitude depends on many factors (gas pipeline diameter, length, terrain conditions, pipeline age, etc.). Such circumstances cause the loss to be regarded as a random variable.

The failure prevention is possible as a result of highquality repair services (replacement works, or repair of the gas pipeline whose parameter value is close to the limit), which requires both financial resources and highly educated staff. Now the equipment used in the system of natural gas transportation and storage in Ukraine is not only physically but also morally obsolete. This results in the frequent stoppages in work, emergencies, operating at noneconomical modes. This causes an increase in the cost of fuel and energy resources, an increase in their cost and technological losses.

Since gas transportation and storage is an energyintensive process (the share of FER costs in the total cost of gas transportation is $60-80 \%$ ), it is of primary importance for the enterprise to carry out technological re-equipment of production, improvement of technologies that is not possible without highly professional staff and financial investments.

In order to increase the reliability level of Ukrainian gas transportation system functioning we offer:

A. To introduce a system of the following technical and technological measures:

- the pipelines renovation and modernization;

- thermal insulation and corrosion protection improvement.

These measures will prevent accidents on the linear part of the pipeline, increase their resistance to adverse climatic conditions, reduce gas pollution during transportation and prevent gas leakage. All this will optimize the operation of the system as a whole, reduce the loss of FER, and therefore the overall cost of the enterprise.

- introduction of new energy-efficient engines.

Most of the engines that drive compressor stations are gas turbines. Moreover, their efficiency is very low, does not even reach $25 \%$, so it should be replaced with more energyefficient one. The domestic market includes a sufficient supply level of gas turbine engines with better technical parameters and higher efficiency.

- $\quad$ reduction of energy losses caused by changes in gas pipeline load.

The level of automatic control and regulation of the work should be increased and automated systems of self-start and shutdown of gas-pumping units have to be implemented.

B. For the implementation of these measures it is necessary to perform a number of socio-economic tasks.

In particular, in order to control deviations from the FER spending norms, they pre-design and establish them. The primary of the socio-economic measures should be:

- economically justified norms of the FER unit costs development.

Carrying out a deep analysis of the existing equipment, to study the technical characteristics, to determine the optimum operating modes and the load levels are offered as a base for economically justifiable cost standards for energy sources implementing.

- the system of bonuses and personal responsibility of employees introducing. 
Material incentives will include rewarding employees for efficient use of energy resources. The share of premiums in the saved of FERs cost must be set. Employees should also be encouraged to increase the efficiency of FER use, to implement energy-saving technologies etc.

$C$. The quintessence of work of the gas transport enterprise should be the system of effective flexible management, capable to provide quick decisions under different conditions concerning conducting efficient economic activity.

\section{CONCLUSIONS}

Thus, the conducted study of the gas transmission lines showed the following priority tasks for gas transportation companies: sound technical and economic rationing, attracting investment for the development of both the industry as a whole and human development, expert management etc. Substantiation of effective management decisions and reforms requires not only the accurate quantitative assessment of the level of gas supply reliability and the impact of individual threats, but also an absolute and qualitative assessment, which will allow to model the individual scenarios of reform measures. Continuous monitoring with the forecasted parameters of the gas pipelines combined will allow not only to reduce the accident rate on the main pipelines, but also to save significant financial resources and gain economic impact through technical, economic, social and environmental measures in order to improve the reliability of gas transportation system operation and energy security of Ukraine.

\section{REFERENCES}

1] National Security Strategy of Ukraine approved by Decree of the President of Ukraine No. 105/2007 dated 12.02.07. [Online] Available: http://zakon4.rada.gov.ua/laws/show/105/2007

[2] V. Dergachova \& N. Pysar, "Implementation of the market approach to the processes of management of the energy sector of ukrainian economy under conditions of european integration", EasternEuropean Journal of Enterprise Technologies, 3(3-93), 40-49, 2018. doi:10.15587/1729-4061.2018.133437
[3] E. Butler, "Conclusion: Central and eastern european energy security more than Russia", Understanding energy security in central and eastern Europe: Russia, transition and national interest, pp. 222-231, 2018. doi:10.4324/9781315651774

[4] M. Hassan, M. Khan Afridi \& M. Irfan Khan, "Energy policies and environmental security: A multi-criteria analysis of energy policies of pakistan", International Journal of Green Energy, 16(7), 510-519, 2019. doi:10.1080/15435075.2019.1593177

[5] R. Magomedov, M. Paizulaev \& E. Gebel, "Reliability evaluation of oil pipelines operating in aggressive environment", AIP Conference Proceedings1876, 020084, 2017. https://doi.org/10.1063/1.4998904

[6] Q. Zhou, W. Wu, L. Dongpeng, K. QiaoQiao, "Estimation of corrosion failure likelihood of oil and gas pipeline based on fuzzy logic approach", Engineering Failure Analysis, Volume 70, December 2016, Pages 48-55. https://doi.org/10.1016/j.engfailanal.2016.07.01

[7] W. Yu, J. Gong, S. Song, W. Huang, Y. Li, J. Zhang, B. Zhang, Y. Wen, X. Duan, "Gas supply reliability analysis of a natural gas pipeline system considering the effects of underground gas storages", Applied Energy, 252, 2019. doi: 10.1016/j.apenergy.2019.113418

[8] P. Eser, N. Chokani, R. "Abhari, Impact of Nord Stream 2 and LNG on gas trade and security of supply in the European gas network of 2030", Applied Energy, 238, pp. 816-830, 2019. doi: 10.1016/j.apenergy.2019.01.068

[9] N. Ilkevich, T. Dzyubina, Z. Kalinina, "Development of analysis methods for ensuring the reliability of gas distribution systems in the problems of complex energy supply", E3S Web of Conferences, 102, № 02005, 2019. doi: 10.1051/e3sconf/201910202005

[10] Z. Luo, Y. Xi, \& H. Wang, "Research on comprehensive quantitative risk-assessment of urban nature gas pipeline", Paper presented at the International Conference on Management Science and Engineering - Annual Conference Proceedings, 2013,2196-2202. doi:10.1109/ICMSE.2013.6586568

[11] Z. Han \& W. Weng, "An integrated quantitative risk analysis method for natural gas pipeline network", Journal of Loss Prevention in the Process Industries, 23(3), 428-436, 2010. doi:10.1016/j.jlp.2010.02.003

[12] L. Manian \& A. Hodgdon, "Pipeline integrity assessment and management", Materials Performance, 44(2), 18-22, 2005.

[13] S. Tregub, V. Yakushev, S. Khan, S. Arutyunov \& V. Volsky, "Alternative UGS technologies - ways of realization", Paper presented at the International Gas Union World Gas Conference Papers, 1, 2006, 435-444, 